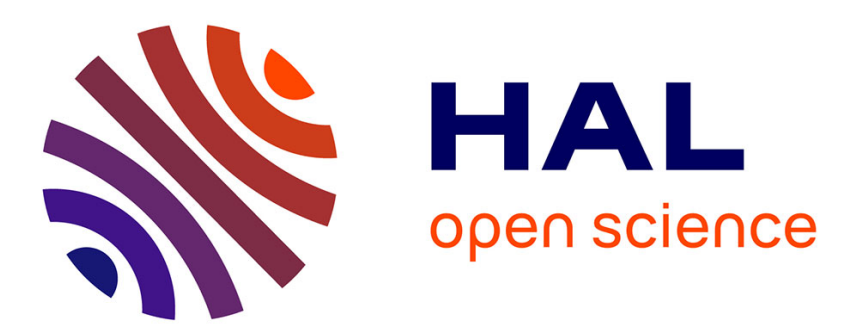

\title{
Theoretical study of the bonding between aminocarbene and main group elements
}

Gilles Frison, Alain Sevin

\section{To cite this version:}

Gilles Frison, Alain Sevin. Theoretical study of the bonding between aminocarbene and main group elements. Journal of the Chemical Society Perkin Transactions 2, 2002, pp.1692-1697. 10.1039/b204688a . hal-00463354

\section{HAL Id: hal-00463354 \\ https://hal.science/hal-00463354}

Submitted on 11 Mar 2010

HAL is a multi-disciplinary open access archive for the deposit and dissemination of scientific research documents, whether they are published or not. The documents may come from teaching and research institutions in France or abroad, or from public or private research centers.
L'archive ouverte pluridisciplinaire HAL, est destinée au dépôt et à la diffusion de documents scientifiques de niveau recherche, publiés ou non, émanant des établissements d'enseignement et de recherche français ou étrangers, des laboratoires publics ou privés. 


\title{
Theoretical study of the bonding between aminocarbene and main group elements $\uparrow$
}

\author{
Gilles Frison * and Alain Sevin \\ Laboratoire de Chimie Théorique, UMR 7616, Université Pierre et Marie Curie, \\ CC 137, 4 Place Jussieu, 75252 Paris Cedex 05, France
}

Received (in Cambridge, UK) 15th May 2002, Accepted 23rd July 2002

First published as an Advance Article on the web 7th August 2002

\begin{abstract}
B3LYP/6-31G* calculations were carried out on adducts formed by the interaction of a cyclic unsaturated aminocarbene with carbenoid moieties $\mathrm{CH}_{2}, \mathrm{SiH}_{2}, \mathrm{NH}, \mathrm{PH}, \mathrm{O}$ or $\mathrm{S}$. The bonding mode has been described using the Natural Bond Orbital (NBO) partitioning schemes, the Charge-Decomposition Analysis (CDA) and the topological analysis of the Electron Localization Function (ELF). A donor-acceptor interaction with a substantial $\pi$ backbonding of the carbenoid moiety is observed in the case of $\mathrm{CH}_{2}, \mathrm{SiH}_{2}, \mathrm{PH}$ and $\mathrm{S}$. The bond-description has been correlated with the bond length, the bond dissociation energy and the aromaticity of the carbene ring obtained by Nucleus-Independent Chemical Shift (NICS) calculation.
\end{abstract}

\section{Introduction}

Since their first synthesis by Arduengo and co-workers in 1991, imidazol-2-ylidenes have been the subject of a growing interest, especially in the field of catalysis where they could be used instead of phosphines as ligands. ${ }^{2}$ Besides this possibility of coordination to transition metals, aminocarbenes may also bind to main group elements. ${ }^{3}$ Among the various compounds thus obtained, those resulting from the bonding of an aminocarbene with a fragment possessing an electronic structure isolobal to a carbene (named carbenoid thereafter) have retained our attention. As far as we know, such a structure could be indeed found for $\mathrm{CR}_{2},{ }^{4,5} \mathrm{SiR}_{2},{ }^{6} \mathrm{GeR}_{2},{ }^{7} \mathrm{SnR}_{2},{ }^{8} \mathrm{PbR}_{2},{ }^{9} \mathrm{NR},{ }^{10} \mathrm{PR},{ }^{11,12}$ AsR $,{ }^{12} \mathrm{O},{ }^{13} \mathrm{~S},{ }^{14} \mathrm{Se}^{15}$ and $\mathrm{Te}{ }^{5,16}$ carbenoids. In these compounds, a formal double bond exists between the carbene and the carbenoid end. This bond is generally not significantly shorter than the corresponding single bond and exhibits a neat polarity towards the negative extremity of the carbenoid, as displayed in the limiting resonance structures $\mathbf{A}$ and $\mathbf{B}$ of Fig. 1.

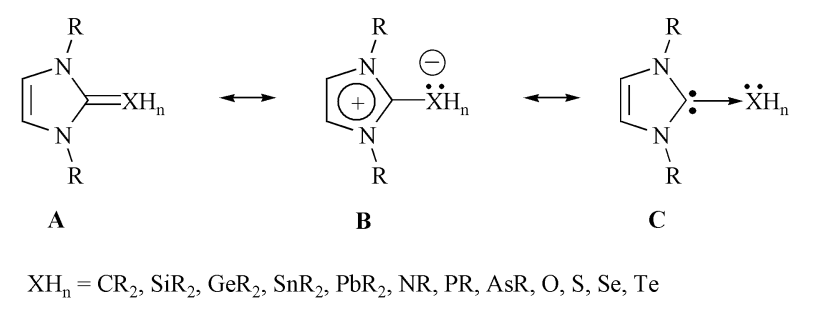

Fig. 1 Limiting resonance structures involved in double bond between imidazol-2-ylidene and main group element.

When the carbenoid is a phosphinidene group PR, Cowley et al. have proposed, by analogy with transition metal carbene complexes ${ }^{17}$ another resonance form (C, Fig. 1). ${ }^{18}$ These authors suggested that the bonding between aminocarbene and phosphinidene is best described as a donor-acceptor bond, as in Fischer carbenes, whereas typical phosphaalkenes possess a covalent double bond between a triplet carbene and a triplet

$\uparrow$ Electronic supplementary information (ESI) available: Cartesian coordinates, absolute energies (at B3LYP/6-31G* and B3LYP/ 6-31 $+\mathrm{G}^{* *} / / \mathrm{B} 3 \mathrm{LYP} / 6-31 \mathrm{G}^{*}$ levels) and Zero-Point Energy (ZPE) of compounds 1-6. See http://www.rsc.org/suppdata/p2/b2/b204688a/

+ Present address: Laboratoire DCMR, Ecole Polytechnique, 91128 Palaiseau Cedex, France. E-mail: gilles.frison@polytechnique.org; Fax: + $0033(0) 169333041$. phosphinidene, as in Schrock carbenes. The same kind of donor-acceptor bonding model has also been proposed for aminocarbene dimers, ${ }^{19}$ aminocarbene-aminosilylene ${ }^{6}$ or aminocarbene-germylene ${ }^{7}$ adducts.

Recently, we have examined theoretically the coordination of phosphinidene to various diaminocarbenes and brought some precision to the description of the bonding mode. ${ }^{20}$ We have shown that $\sigma$-donation of the in-plane carbene lone pair to the phosphinidene moiety is completed by a substantial $\pi$-back bonding from the $\mathrm{P}$ valence space to the cycle. The smallest $\pi$-back-bonding is obtained in the case of imidazol-2-ylidene due to the delocalization of the nitrogen lone pairs, which participates to the ring aromaticity.

During this study we have been interested in the possibility of extending this description to other aminocarbene-carbenoid adducts. The following questions have retained our attention: for which carbenoid is the donor-acceptor bond description valid? Which factor governs the preference for a donoracceptor or a covalent bond? What is the influence of bonding on the geometric structures? In the case of a donor-acceptor bond; what is the intensity of back-donation? Our work is aimed at answering these questions for carbenoids bearing atoms of the second $\left(\mathrm{CH}_{2}, \mathrm{NH}, \mathrm{O}\right)$ and third $\left(\mathrm{SiH}_{2}, \mathrm{PH}, \mathrm{S}\right)$ rows of the periodic table.

\section{Methodology}

All calculations were carried out with the GAUSSIAN $94^{21}$ or GAUSSIAN $98^{22}$ suite of programs. Geometry optimizations of all compounds studied were performed, with no symmetry constraints, using Becke's hybrid three-parameter exchange functional and Lee, Yang, and Parr's nonlocal correlation functional (B3LYP) ${ }^{23}$ using the $6-31 G^{*}$ basis set ${ }^{24}$ containing six Cartesian d functions. A vibrational analysis was performed after optimization of each stationary point found, to confirm its identity as an energy minimum (NIM $=0)$. Inspection of the carbene-carbenoid interaction was performed using the Natural Bond Orbital (NBO) partitioning scheme, ${ }^{25}$ the Charge-Decomposition Analysis (CDA) ${ }^{26}$ and the topological analysis of the Electron Localization Function (ELF) ${ }^{27}$ based on the B3LYP/6-31G* wave function.

The NBO analysis is based on a method for optimally transforming a given wavefunction into a localized form, corresponding to the one-center (core and lone-pair) and two-center (bond) parts of the chemist's Lewis structure picture. It has the 
advantage of transforming the delocalized, canonical, molecular orbitals, which are distributed over the entire molecule, into localized orbitals that represent a more "chemical" view of the system. Several steps from the one-electron density matrix give the set of natural bond orbitals (NBOs). This set, corresponding to the one for which the two-center natural bond orbitals subblock accommodates most electrons, is then given as the optimal Lewis structure of the molecule. It has to be stressed that this partitioning procedure induces an artificial cutoff between bonds and lone pairs. Bond polarities have thus been discussed on the basis of natural localized molecular orbitals (NLMOs) derived from the NBOs.

In the ELF method, the molecular space is divided into various types of basins located around an attractor. Core basins, labeled $\mathrm{C}(\mathrm{X})$ and located around the heavy atoms, which are typical of the $\mathrm{K}$ shell for $\mathrm{C}, \mathrm{N}$ and $\mathrm{O}$ atoms and $\mathrm{K}$ and $\mathrm{L}$ shells for $\mathrm{Si}, \mathrm{P}$ and $\mathrm{S}$ atoms, will not be treated here for the sake of conciseness. To a good approximation, they may be considered as remaining independent of the actual substitution and bonding pattern. A given valence basin will be labeled as one of the following: (i) $\mathrm{V}(\mathrm{X})$ when it only shares a boundary with a core basin and thus contains electrons that are not involved in a bonding process. This corresponds to the usual Lewis language for nonbonding electrons. In this case, the ideal count of electrons is 2 for a "lone pair" or 1 for an "odd electron", depending on the actual case. (ii) V(X, Y) when the basin shares a boundary with the cores of two atoms X and Y. Such a basin is typical of a bond between $\mathrm{X}$ and $\mathrm{Y}$. We will see in the coming sections that its population may vary significantly, according to the actual nature of the bond. Though the classical MO language distinguishes $\sigma$ and $\pi$ contributions to bonding, the ELF analysis, which is based on the total electronic density, characterizes basins and attractors without separating these types of contribution. For example when dealing with alkenes, two $\mathrm{V}(\mathrm{C}, \mathrm{C})$ basins are observed at the usual standard bond length, separately lying above and below the double-bond local plane. ELF calculations were achieved using the wfn output of B3LYP runs, using the TopMod series of programs. ${ }^{28}$

The CDA method may be regarded as a "quantified"Dewar-Chatt-Duncanson ${ }^{29}$ model providing information about the donation, back-donation, and repulsive interactions in donor-acceptor compounds. This is achieved, in the present case, by inspecting the orbital contributions to the charge distributions in the aminocarbene-carbenoid adduct by (i) the mixing of the filled orbitals of the aminocarbene with the unfilled orbitals at the carbenoid (donation); (ii) the mixing of the unfilled orbitals of the aminocarbene with the filled orbitals at the carbenoid (back-donation); (iii) the mixing of the filled orbitals of the aminocarbene with the filled orbitals at the carbenoid (repulsive polarization); (iv) the mixing of the unfilled orbitals of the aminocarbene with the unfilled orbitals at the carbenoid (residual term). One of the chief advantages of CDA is that it is correct only for compounds that are donoracceptor adducts. All others possess large residual terms, which is a physically unreasonable result and indicates that the compounds could not be described as the result of interaction between closed-shell fragments. The program CDA 2.1 has been employed for the CDA calculations. ${ }^{30}$

The aromatic character was evaluated by computing the nucleus-independent chemical shift (NICS, GIAO-SCF/6$\left.31+\mathrm{G}^{*} / / \mathrm{B} 3 \mathrm{LYP} / 6-31 \mathrm{G}^{*}\right)$ at the center of the five-membered ring. ${ }^{31}$ The dissociation energies have been computed at the same level of calculation as in ref. 6 (B3LYP/6-311+G**) based on our B3LYP/6-31G* geometries.

\section{Results and discussion}

\section{Geometries, aromaticity and bond energies}

Fig. 2 exhibits the optimized structures of the aminocarbenecarbenoid adducts $\mathbf{1}-\mathbf{6}$. The calculations show that compounds
Table 1 B3LYP/6-31G* bond length (in $\AA$ ) of $\mathrm{H}_{3} \mathrm{C}-\mathrm{X}$ and $\mathrm{H}_{2} \mathrm{C}=\mathrm{Y}$ $\left(\mathrm{X}=\mathrm{CH}_{3}, \mathrm{SiH}_{3}, \mathrm{NH}_{2}, \mathrm{PH}_{2}, \mathrm{OH}, \mathrm{SH} ; \mathrm{Y}=\mathrm{CH}_{2}, \mathrm{SiH}_{2}, \mathrm{NH}, \mathrm{PH}, \mathrm{O}, \mathrm{S}\right)$

\begin{tabular}{lcccccc}
\hline & CC & CSi & CN & CP & CO & CS \\
\hline Single bond & 1.530 & 1.889 & 1.466 & 1.877 & 1.419 & 1.836 \\
Double bond & 1.331 & 1.710 & 1.270 & 1.675 & 1.206 & 1.618 \\
\hline
\end{tabular}

Table 2 Dissociation energies ${ }^{a}$ of the carbene-carbenoid adduct 1-6 and of the corresponding parent single and double bond with respect to the electronic ground state of the fragments ${ }^{b}$

\begin{tabular}{|c|c|c|c|c|c|c|}
\hline & $\mathrm{CC}$ & $\mathrm{CSi}$ & $\mathrm{CN}$ & $\mathrm{CP}$ & $\mathrm{CO}$ & CS \\
\hline & & 334 & 23 & 4 & 353 & 276 \\
\hline Carbene-carbenoid & 4 & 194 & 09 & & 572 & 35 \\
\hline Double bond & 702 & 438 & 631 & 474 & 727 & 51 \\
\hline \multicolumn{7}{|c|}{$\begin{array}{l}{ }^{a} \mathrm{~B} 3 \mathrm{LYP} / 6-311+\mathrm{G}^{* *} / / \mathrm{B} 3 \mathrm{LYP} / 6-31 \mathrm{G}^{*} \text { energies, corrected with } \mathrm{ZPE} \\
\text { obtained at } \mathrm{B} 3 \mathrm{LYP} / 6-31 \mathrm{G}^{*}(\text { scaling factor } 0.98)^{32} \text { in kJ mol }{ }^{-1} \cdot{ }^{b} \mathrm{Singlet} \\
\text { state of } \mathrm{SiH}_{2} \text { and the free aminocarbene, doublet state of } \mathrm{CH}_{3}, \mathrm{SiH}_{3} \text {, } \\
\mathrm{NH}_{2}, \mathrm{PH}_{2}, \mathrm{OH}, \mathrm{SH} \text {, triplet state of } \mathrm{CH}_{2}, \mathrm{NH}, \mathrm{PH}, \mathrm{O} \text { and } \mathrm{S} \text {. }\end{array}$} \\
\hline
\end{tabular}

4-6 are strictly planar while $\mathbf{1}$ and $\mathbf{3}$ are almost planar with a substantial pyramidality from each nitrogen of the cycle (the sum of the bond angles around each $\mathrm{N}$ equals $351.4^{\circ}$ in $\mathbf{1}$, $359.4^{\circ}$ and $359.9^{\circ}$ in $\mathbf{3}$ ). Compound $\mathbf{2}$ has a non-planar structure, the silylene plane being almost orthogonal to the carbene plan. These calculated molecular shapes agree well with available experimental X-ray structures. 4,4'-Methylenebis(1,3,5-trimethyl-4-imidazolin-2-one) ${ }^{13 a}$ and substitued ${ }^{14 b}$ or semihydrated ${ }^{14 c}$ imidazoline-2-thione, respectively analogues of 5 and $\mathbf{6}$, show planar carbene rings, as well as methylsubstituted analogues of $\mathbf{1}^{4}$ and $3{ }^{10}$ The non-planarity of experimental analogues of $4,{ }^{11,12}$ as well as the shorter calculated $\mathrm{P}-\mathrm{C}$ bond length ${ }^{20 b}$ have been shown to result from steric hindrance. An experimental structure comparable to $\mathbf{2}$ has been recently published. ${ }^{6}$ This $N$-heterocyclic carbene- $N$-heterocyclic silylene adduct shows that the two rings are almost perpendicular.

The agreement between experimental and calculated bond lengths is also quite good (Fig. 2), even if substituent effects are not taken into account. The aminocarbene-carbenoid bond length is very well reproduced for second row carbenoids $(\mathbf{1}, \mathbf{3}$, 5) for which experimental structures containing only alkyl chains on the carbene ring are available., ${ }^{40,13 a}$ The structural change produced by substituting the hydrogens at $\mathrm{Si}$ by amino groups in 2 has been studied. ${ }^{6}$ Calculation at the B3LYP/6$311+\mathrm{G}(\mathrm{d}, \mathrm{p})$ level gives a $1.927 \AA \mathrm{C}-\mathrm{Si}$ bond length for $\mathbf{2}$ and a $2.024 \AA \mathrm{C}-\mathrm{Si}$ bond length for the unsubstituted $N$-heterocyclic carbene- $N$-heterocyclic silylene adduct, in better agreement with the experiment. Finally, the slightly shorter $\mathrm{C}-\mathrm{S}$ bond length of 6 (1.676 Å) compared to experimental values (1.696$1.698 \AA$ ) could be explain by the presence of a hydrogen bond in crystallographic structure formed between $\mathrm{S}$ and a hydrogen from either a second adduct ${ }^{14 b}$ or a water molecule. ${ }^{14 c}$ This intermolecular bond indeed probably lowers the $\pi$-back-bonding of the $\mathrm{S}$ atom on the ring (vide infra) and thus prevents a slight decrease of the $\mathrm{C}-\mathrm{S}$ bond length.

Table 1 shows the bond lengths of the unsubstituted single and double bond between $\mathrm{C}$ and $\mathrm{C}, \mathrm{Si}, \mathrm{N}, \mathrm{P}, \mathrm{O}$ or $\mathrm{S}$. The carbene-carbenoid bond lengths are always longer than the corresponding double bonds. For $\mathbf{1}, \mathbf{3}$ and $\mathbf{5}$, the increase is relatively small (about $+0.02 \AA$ ) whereas it is more pronounced for $\mathbf{6}(+0.058 \AA), \mathbf{4}(+0.088 \AA)$ and especially for $\mathbf{2}(+0.222$ $\AA$ ). Indeed the last compound has a C-Si bond length (1.932 ̊) longer than the corresponding $\mathrm{C}-\mathrm{Si}$ single bond (1.889 $\AA$ ) (Table 1 and Fig. 1).

Table 2 gives the theoretically predicted carbene-carbenoid bond dissociation energies. These values indicate that the dissociation energies of carbene-carbenoid bonds are always 


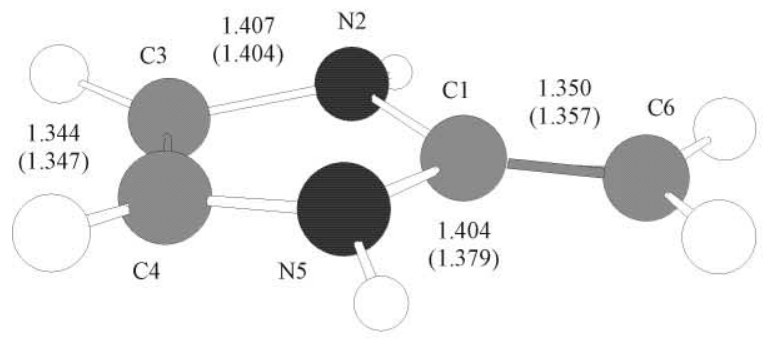

1

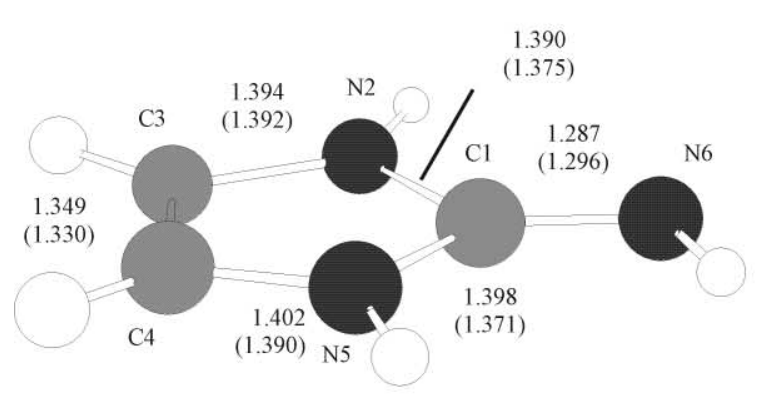

3

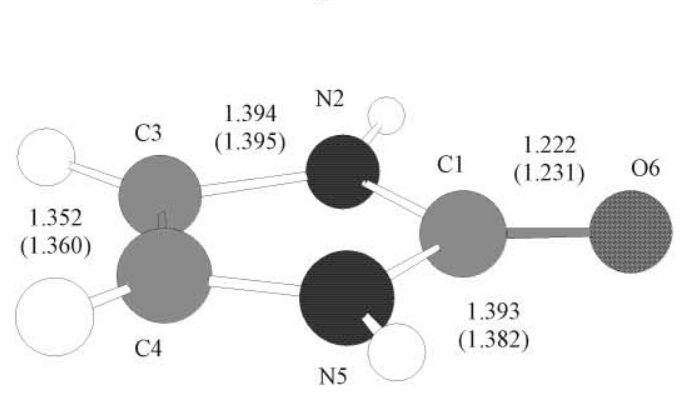

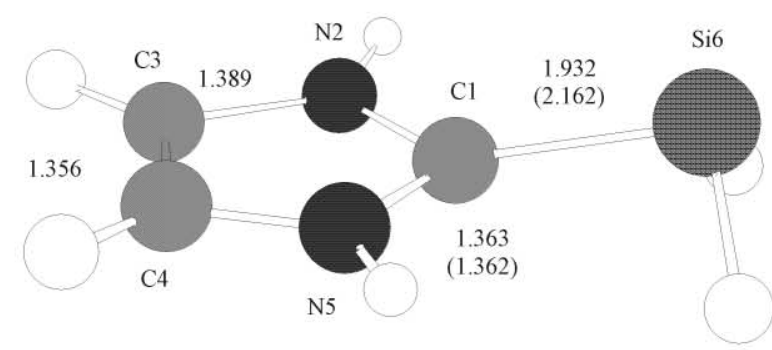

2

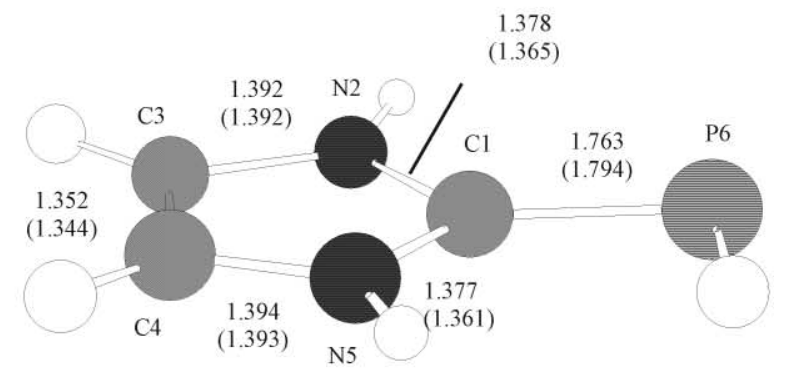

4

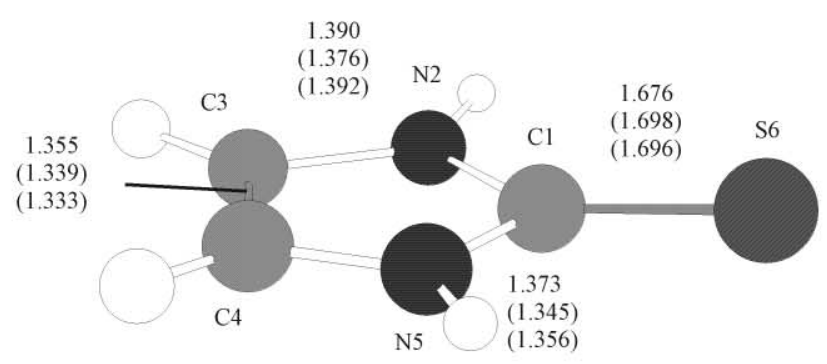

Fig. 2 Optimized equilibrium structures (B3LYP/6-31G*) of compounds 1-6. Experimental values of substituted compounds available are shown in parentheses: $1,3,4,5$-tetramethyl-2-methyleneimidazoline ${ }^{4}$ for $\mathbf{1}, N$-heterocyclic carbene- $N$-heterocyclic silylene ${ }^{6}$ for $\mathbf{2}$, 2-imino-1,3-dimethylimidazoline ${ }^{10}$ for 3, 1,3,4,5-tetramethyl-2-phenylphosphinideneimidazoline ${ }^{11}$ for 4, 4,4'-methylenebis(1,3,5-trimethyl-4-imidazolin-2-one) ${ }^{13 a}$ for 5, imidazoline-2-thione semihydrate ${ }^{14 c}$ (top parentheses) and 1,3-dimethylimidazoline-2-thione ${ }^{14 b}$ (bottom parentheses) for 6.

Table 3 Aromaticity measurements (NICS, GIAO-HF/6-31+G*//B3LYP/6-31G*) and results of the NBO analysis (results for the corresponding parent double bond are given in parentheses, B3LYP/6-31G*) of the carbene-carbenoid adducts 1-6

\begin{tabular}{|c|c|c|c|c|c|c|}
\hline & \multirow[b]{2}{*}{ NICS } & \multicolumn{2}{|c|}{$\% \mathrm{C}$ in $\mathrm{C}(1)-\mathrm{X}(6)$ bond $^{a}$} & \multicolumn{2}{|c|}{$\% \mathrm{X}$ in $\mathrm{C}(1)-\mathrm{X}(6)$ bond $^{a}$} & \multirow{2}{*}{$\begin{array}{l}\text { Charge } \\
\mathrm{XH}_{n}\end{array}$} \\
\hline & & $\sigma$ bond & $\pi$ bond & $\sigma$ bond & $\pi$ bond & \\
\hline 1 & -6.8 & $51.3(50.0)$ & $42.4(49.9)$ & $48.1(50.0)$ & $57.3(49.9)$ & $-0.22(0.00)$ \\
\hline 2 & -12.2 & $77.4(69.4)$ & $5.7(59.7)$ & $21.0(30.4)$ & $91.0(40.3)$ & $-0.19(0.58)$ \\
\hline 3 & -9.3 & $43.5(40.9)$ & $34.0(43.2)$ & $56.2(59.0)$ & $65.9(56.8)$ & $-0.47(-0.26)$ \\
\hline 4 & -10.2 & $68.1(63.8)$ & $31.7(51.9)$ & $30.9(36.1)$ & $68.1(48.1)$ & $-0.11(0.34)$ \\
\hline 5 & -10.5 & $35.8(33.6)$ & $27.6(35.5)$ & $64.0(66.3)$ & $72.3(64.5)$ & $-0.66(-0.49)$ \\
\hline 6 & -11.2 & $60.3(56.0)$ & $26.3(43.9)$ & $39.0(43.9)$ & $73.5(56.1)$ & $-0.27(0.07)$ \\
\hline
\end{tabular}

${ }^{a}$ Percentage of the NLMO considered on $\mathrm{C}(1)$ or $\mathrm{X}(6)$. The sum of the contribution on $\mathrm{C}(1)$ and $\mathrm{X}(6)$ is not exactly $100 \%$ due to some small contributions from other atoms.

lower than these of the corresponding double bond. For $\mathbf{4}$ and especially for $\mathbf{2}$, the dissociation energy is even smaller than for the corresponding single bond.

Let us now focus our attention on the carbene ring bond lengths. We observe an increase of the four $\mathrm{C}-\mathrm{N}$ bond lengths and a concomitant decrease of the $\mathrm{C}-\mathrm{C}$ bond according to the order $\mathbf{2} \rightarrow \mathbf{6} \rightarrow \mathbf{4} \rightarrow \mathbf{5} \rightarrow \mathbf{3} \rightarrow \mathbf{1}$. The change along this series results from a decrease of delocalization on the carbene ring. On this ground, a comparison with the free carbene ${ }^{33}$ shows that $\mathbf{2}$ would possess quite the same aromaticity. ${ }^{34}$
The NICS calculation at the center of the carbene ring (Table 3) confirms this trend. The aminocarbene-carbenoid adducts possess an aromatic character which is inferior to that of the free carbene. ${ }^{33}$ The less aromatic compounds are $\mathbf{3}$ and more especially 1, for which small structural distortions from the carbene ring planarity are calculated.

\section{Analysis of the bonding situation}

The results of the NBO analysis are listed in Table 3. The optimal Lewis structure predicted by the NBO partition scheme for 


\begin{tabular}{|c|c|c|c|c|c|c|}
\hline & \multicolumn{6}{|l|}{$\mathrm{XH}_{n}$} \\
\hline & $\mathrm{CH}_{2}$ & $\mathrm{SiH}_{2}$ & $\mathrm{NH}$ & $\mathrm{PH}$ & $\mathrm{O}$ & $\mathrm{S}$ \\
\hline \multicolumn{7}{|l|}{$\mathrm{CH}_{2}=\mathrm{XH}_{n}$ compounds } \\
\hline $\mathrm{V}(\mathrm{C}, \mathrm{X})$ & $3.42^{a}$ & $3.58^{a}$ & $3.00^{a}$ & $2.96^{a}$ & 2.31 & $2.62^{a}$ \\
\hline $\mathrm{V}(\mathrm{X})$ & - & - & 2.62 & 2.69 & $5.20^{a}$ & $5.00^{a}$ \\
\hline \multicolumn{7}{|l|}{ Aminocarbene- $\mathrm{XH}_{n}$ adducts } \\
\hline $\mathrm{V}(\mathrm{C} 1, \mathrm{X} 6)$ & $3.52^{a}$ & 2.50 & 2.79 & 2.60 & 2.13 & 2.43 \\
\hline $\mathrm{V}(\mathrm{X} 6)$ & 0.37 & 1.92 & 3.27 & $3.76^{a}$ & $5.74^{a}$ & $5.76^{a}$ \\
\hline $\mathrm{V}(\mathrm{C} 1, \mathrm{~N} 2 / 5)$ & 2.06 & 2.34 & 2.08 & 2.11 & 2.19 & 2.33 \\
\hline $\mathrm{V}(\mathrm{N} 2 / 5, \mathrm{C} 3 / 4)$ & 1.76 & 1.95 & 1.80 & 1.87 & 1.87 & 1.93 \\
\hline $\mathrm{V}(\mathrm{C} 3, \mathrm{C} 4)$ & $3.68^{a}$ & $3.54^{a}$ & $3.64^{a}$ & $3.58^{a}$ & $3.62^{a}$ & $3.56^{a}$ \\
\hline $\mathrm{V}(\mathrm{N} 2 / 5)$ & $1.61+0.32^{b}$ & $1.18^{a}$ & $1.06+0.78^{b}$ & $1.58^{a}$ & $1.62^{a}$ & $1.30^{a}$ \\
\hline
\end{tabular}

${ }^{a}$ Sum of the population of two identical basins. ${ }^{b}$ The nitrogen pyramidalization induces two non-identical basins. Basins population in electrons.

adducts $\mathbf{1}$ and 3-6 yields a carbene-carbenoid couple of $\sigma$ and $\pi$ bonds, while 2 only has a $\sigma$ bond. ${ }^{35}$ The examination of the bond polarities at the basis of natural localized molecular orbitals (NLMOs) gives more precise information on the bonding (Table 3). The $\mathrm{C}(1)-\mathrm{X}(6)(\mathrm{X}=\mathrm{C}, \mathrm{Si}, \mathrm{N}, \mathrm{P}, \mathrm{O}, \mathrm{S}) \sigma$ bond of compounds 1-6 exhibits a variable polarity depending on the electronegativity of $\mathrm{X}$. Compound $\mathbf{2}$ shows the higher polarity towards C (only $21 \%$ is at the $\mathrm{Si}$ end) whereas the lower polarity towards $\mathrm{C}$ is calculated for $\mathbf{5}(64 \%$ is at the $\mathrm{O}$ atom). The comparison of the NLMOs $\sigma$ bond between the parent double bond and 1-6 (Table 3) reveals that the $\mathrm{C}-\mathrm{X} \sigma$ bond is always more polarized towards $\mathrm{C}$ in the latter compounds than in the former. The changes in polarity are however relatively weak (the maximum change was calculated for $\mathbf{2}$ with an increase from 69 to $77 \%$ ).

The opposite result is observed for the $\pi$ system. The $\mathrm{C}(1)$ $\mathrm{X}(6) \pi$ bond of $\mathbf{1}$ and $\mathbf{3 - 6}$ is polarized towards the carbenoid (57-73\% is at the $\mathrm{X}$ end). The NBO bonding pattern for 2 suggests that the $\mathrm{Si}-\mathrm{C} \pi$ system is even more polarized towards the carbenoid end, because the optimal Lewis structure bears a silicon lone pair $\mathrm{p}(\pi)$ orbital rather than a $\pi$ bond. This "parent" natural bond orbital (NBO) gives indeed a natural localized molecular orbital (NLMO) which is mostly located at the $\mathrm{Si}$ end $(91 \%)$. This NLMO is strongly delocalized, having only about a $91 \%$ contribution from the localized $\mathrm{Si}(6)$ parent lone pair NBO, with "delocalization tails" composed primarily of contribution $(5.7 \%)$ from $\mathrm{C}(1)$, and also smaller contributions $(\sim 1,6 \%$ each) from both nitrogens. The $\pi$ polarity towards the carbenoid, compared to that of parent classical double bonds, is enhanced in $\mathbf{1}, \mathbf{3}, \mathbf{5}$ and $\mathbf{6}$, and shows the reverse trend in 2 (91 instead of 40\% at the Si end) and 4 (68 instead of $48 \%$ at the $\mathrm{P}$ end). It is noteworthy that the change in polarity is higher for $\pi$ than for $\sigma$ bonds. Furthermore, we observed that the stronger the change in $\pi$ polarity (60 to $6 \%$ with $\mathrm{Si}, 52$ to $32 \%$ with P, 44 to $26 \%$ with S), the higher the lengthening of the $\mathrm{C}(1)-\mathrm{X}(6)$ bond compared to the classical double bond.

The calculated atomic charges (Table 3) indicate that the carbenoid fragment is always negatively charged in adducts 1-6. This is not the case for parent double bond where $\mathrm{SiH}_{2}, \mathrm{PH}$ and $\mathrm{S}$ ends are present. In these cases, where the $\mathrm{X}$ substituent possess lower (or almost equal for $\mathrm{S}$ ) electronegativity than $\mathrm{C}$, the $\mathrm{XH}_{n}$ ends are positively charged. These results are in agreement with the well-known better electronic donating ability of aminocarbenes compared to their acceptability.

The topological analysis of the Electron Localization Function (ELF) yields another point of view on the bonding situation in these compounds. While the NBO analysis focuses on the MO structure of the molecules, the ELF analysis considers the total electron-density distribution. The results of the ELF analysis are listed in Table 4. Before examining the data obtained for compounds 1-6, it seems useful to describe ELF results calculated for parent double bonds since they are not always in agreement with the classical Lewis description. The population of basins $\mathrm{V}(\mathrm{C}, \mathrm{X})$ and $\mathrm{V}(\mathrm{X})(\mathrm{X}=\mathrm{C}, \mathrm{Si}, \mathrm{N}, \mathrm{P}, \mathrm{O}, \mathrm{S})$, which respectively correspond to the $\mathrm{C}-\mathrm{X}$ bond and to the $\mathrm{X}$ lone pair, are given in Table 4.

In all cases, the $\mathrm{C}-\mathrm{X}$ bond is populated by less than four electrons, the latter value being expected in the Lewis scheme. The missing electronic density is partly located in the core basins and in the $\mathrm{C}-\mathrm{H}$ and $\mathrm{X}-\mathrm{H}$ bonds. ${ }^{36}$ But, for the main part, it is located in the $\mathrm{X}$ lone pairs which may accommodate more than two electrons due to their wide spatial extension. ${ }^{37}$ In all $\mathrm{H}_{2} \mathrm{C}=\mathrm{XH}_{n}$ compounds studied the $\mathrm{V}(\mathrm{X})$ basins have a population between $2.5(\mathrm{X}=\mathrm{S})$ and 2.7 electrons $(\mathrm{X}=\mathrm{P})$. This accounts for the decrease of population of $\mathrm{V}(\mathrm{C}, \mathrm{X})$ along the sequence: $\mathrm{H}_{2} \mathrm{C}=\mathrm{SiH}_{2}\left(3.58 \mathrm{e}\right.$ ), $\mathrm{H}_{2} \mathrm{C}=\mathrm{CH}_{2}(3.42 \mathrm{e}$ ) (where no lone pair is present), $\mathrm{H}_{2} \mathrm{C}=\mathrm{S}(2.62 \mathrm{e})$ and finally $\mathrm{H}_{2} \mathrm{C}=\mathrm{O}(2.31 \mathrm{e})$ where two lone pairs are located on the heteroatom. It should be pointed out that $\mathrm{H}_{2} \mathrm{C}=\mathrm{O}$ shows only one bonding attractor for the $\mathrm{C}-\mathrm{O}$ bond ${ }^{38}$ whereas others compounds possess two attractors. Recently, Grützmacher and Fässler have proposed to characterize the bond order by the number of bond attractors. ${ }^{39}$ This would indicate that the limit structure E (Fig. 3) best

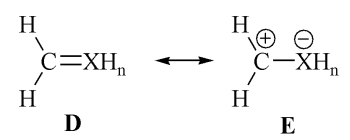

Fig. 3 Limiting resonance structures involved in parent double bonds.

describes $\mathrm{H}_{2} \mathrm{C}=\mathrm{O}$ whereas $\mathrm{H}_{2} \mathrm{C}=\mathrm{XH}_{n}\left(\mathrm{XH}_{n}=\mathrm{CH}_{2}, \mathrm{SiH}_{2}, \mathrm{NH}\right.$, $\mathrm{PH}, \mathrm{S})$ best correspond to form $\mathbf{D}$.

These results have to be kept in mind when analyzing those obtained for compounds 1-6 (Table 4). In 3-6, the C(1)-X(6) bond is slightly depopulated (by about $0.2 \mathrm{e}$ ), as compared to the respective parent classical double bond. This depopulation is much more pronounced in 2 (2.50 e instead of $3.58 \mathrm{e}$ in $\mathrm{V}(\mathrm{C}$, $\mathrm{Si}$ ) of $\mathrm{CH}_{2}=\mathrm{SiH}_{2}$ ) whereas the $\mathrm{C}(1)-\mathrm{C}(6)$ bond in $\mathbf{1}$ is slightly more populated than the $\mathrm{C}=\mathrm{C}$ parent double bond of ethylene (3.52 e instead of $3.42 \mathrm{e}$ ). At the same time, the number of non-bonding electrons at the $\mathrm{XH}_{n}$ end increase on going from the classical double bond to the aminocarbene-carbenoid adducts. In the case of the $\mathrm{NH}, \mathrm{PH}, \mathrm{O}$ and $\mathrm{S}$ carbenoid ends, this corresponds to an increase in the population of the $\mathrm{V}(\mathrm{X})$ basins which are already present in the corresponding double bond. It is noteworthy that the phosphorus atom in $\mathbf{4}$ now has two $\mathrm{V}(\mathrm{P} 6)$ basins due to the presence of 3.76 non-bonding electrons which could not be accommodated by only one lone pair. In the case of $\mathbf{1}$ and $\mathbf{2}$, we observe that non-bonding electrons are located respectively on the $\mathrm{CH}_{2}$ and $\mathrm{SiH}_{2}$ carbenoid ends although no lone pair is present in the corresponding classical double bond $\mathrm{CH}_{2}=\mathrm{CH}_{2}$ and $\mathrm{CH}_{2}=\mathrm{SiH}_{2}$. The $\mathrm{V}(\mathrm{C} 6)$ basin of $\mathbf{1}$ is very small and only contains 0.37 e whereas $\mathrm{V}(\mathrm{Si} 6)$ of $\mathbf{2}$ is much more populated with $1.92 \mathrm{e}$.

All the trends of the variation of the basins population indicate that the electronic transfer from the carbenoid fragment to 
Table 5 CDA results for the carbene-carbenoid adducts 1-6 at the B3LYP/6-31G* level

\begin{tabular}{|c|c|c|c|c|c|}
\hline & $\begin{array}{l}\text { Carbene } \longrightarrow \mathrm{XH}_{n} \\
\text { Donation }\end{array}$ & $\begin{array}{l}\mathrm{XH}_{n} \longrightarrow \text { Carbene } \\
\text { Back-donation }\end{array}$ & $\begin{array}{l}\text { Donation/ } \\
\text { back-donation }\end{array}$ & $\begin{array}{l}\text { Carbene } \leftrightarrow \mathrm{XH}_{n} \\
\text { repulsion }\end{array}$ & $\begin{array}{l}\text { Residual } \\
\text { term }\end{array}$ \\
\hline 1 & 0.511 & 0.488 & 1.047 & -0.104 & 0.036 \\
\hline 2 & 0.557 & 0.170 & 3.276 & -0.252 & -0.019 \\
\hline 3 & 0.214 & 0.469 & & -0.031 & 0.192 \\
\hline 4 & 0.593 & 0.339 & 1.749 & -0.309 & 0.003 \\
\hline 5 & 0.363 & 0.601 & & -0.163 & 0.190 \\
\hline 6 & 0.557 & 0.423 & 1.317 & -0.356 & 0.020 \\
\hline
\end{tabular}

the $\mathrm{C}(1)-\mathrm{X}(6)$ bond and the carbene ring is diminished in $\mathbf{1}-\mathbf{6}$ compared to the parent double bond, in good agreement with experimental results which show a nucleophilic carbenoid end. As previously observed for $4,{ }^{20 a}$ the formation of the $\mathrm{C}(1)-\mathrm{X}(6)$ bond is accompanied in 1-6 by a decrease of the population of $\mathrm{V}(\mathrm{C} 1, \mathrm{~N} 2 / 5)$ and $\mathrm{V}(\mathrm{N} 2 / 5, \mathrm{C} 3 / 4)$ and an increase of the population of $\mathrm{V}(\mathrm{N} 2 / 5)$ and $\mathrm{V}(\mathrm{C} 3, \mathrm{C} 4)$, compared to the free carbene. ${ }^{33}$ These variations of population confirm the decrease of delocalization of the nitrogen lone pair in the carbene ring. Indeed, the higher the above change compared to the free carbene, the smaller the ring aromaticity previously calculated.

In order to choose between the various structures $\mathbf{A}-\mathbf{C}$ (Fig. 1), we have used the CDA method, ${ }^{26}$ which decomposes the bonding interaction of fragments into donation and backdonation contributions (Fig. 4). In all cases, the aminocarbene

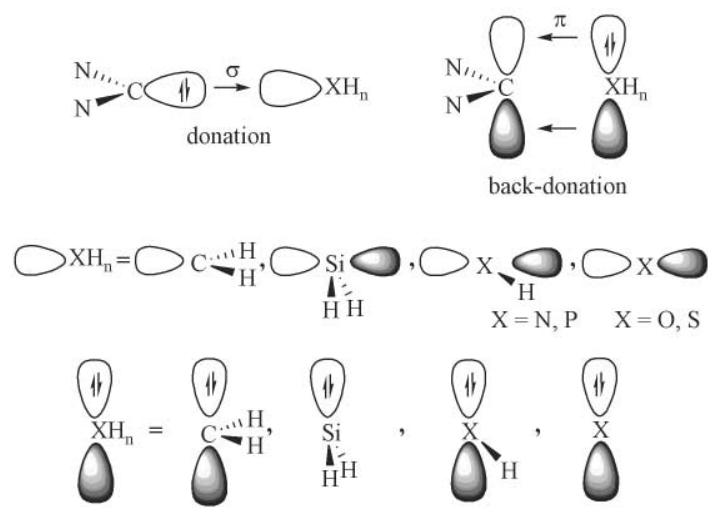

Fig. 4 Schematic representation of the dominant orbital interactions corresponding to the resonance structure $\mathbf{C}$.

fragment has been taken in its singlet ground state with its carbenic lone pair pointing towards the carbenoid end in the plane of the carbene ring. In order to make possible a donoracceptor interaction with the aminocarbene, the carbenoid fragments $\mathrm{CH}_{2}, \mathrm{SiH}_{2}, \mathrm{NH}, \mathrm{PH}, \mathrm{O}$ and $\mathrm{S}$ have been calculated in a closed shell singlet state with an empty $\sigma$-type orbital pointing towards the carbene lone pair and a filled $\pi$-type orbital (Fig. 4). In the case of the $\mathrm{NH}, \mathrm{PH}, \mathrm{O}$ and $\mathrm{S}$ moieties, due to their intrinsic symmetry, these two orbitals are equivalent. The correct orientation of these orbitals is then only a question of axis determination. For $\mathrm{SiH}_{2}$ and $\mathrm{CH}_{2}$, these two orbitals are non-equivalent. In the case of $\mathrm{SiH}_{2}$, the structure of the aminocarbene-carbenoid adducts $\mathbf{2}$ shows a perpendicular arrangement of the fragments. This implies that the empty and filled orbital of the $\mathrm{SiH}_{2}$ carbenoid should be respectively the $\pi$ orbital of the silylene and the Si lone pair. This configuration corresponds to the closed shell singlet ground state of the silylene. For $\mathrm{CH}_{2}$, the singlet closed shell ground state bears an in-plane lone pair, thus directed towards the lone pair of the aminocarbene carbon lone pair in $\mathbf{1}$. We have then used an excited closed shell singlet state with a doubly occupied $\pi$ orbital and an empty in-plane $\sigma$ orbital (Fig. 4). This configuration is located $287 \mathrm{~kJ} \mathrm{~mol}^{-1}$ higher in energy than the singlet ground state, at the B3LYP/6-31G* level, with the geometry parameters of 1 .
Table 5 shows the CDA results for compounds 1-6. The data for 1, 2, 4 and 6 reveal that the residual term is almost zero. This means that these compounds can be reasonably interpreted as adducts between the closed-shell fragments of the aminocarbene and carbenoid $\mathrm{XH}_{n}$. The donation/backdonation ratio for $\mathbf{1}, \mathbf{2}, \mathbf{4}$ and $\mathbf{6}$ suggests that the carbenoid fragment follows the order of back-donating capability: $\mathrm{SiH}_{2}<$ $\mathrm{PH}<\mathrm{S}<\mathrm{CH}_{2}$. This is in good agreement with the trend observed for the $\mathrm{C}(1)-\mathrm{X}(6)$ bond length. Indeed, compared to the classical corresponding double bond, 2 has a higher $\mathrm{C}(1)-$ $\mathrm{X}(6)$ bond length elongation than 4, 6 and especially 1 .

The CDA results for $\mathbf{3}$ and $\mathbf{5}$ differ substantially from the previous ones because the residual terms are large positive numbers. This means that the electronic structure of $\mathbf{3}$ and $\mathbf{5}$ should not be discussed in terms of donor-acceptor interactions between the closed-shell aminocarbene and carbenoid. Inspection of the orbitals that make up the residue term shows that the $\operatorname{sp}(\sigma)$ orbital of the carbenoid, which is unoccupied in the fragment, is a large contributor to the carbene-carbenoid interaction. This means that the $\sigma$-bond is best described by a covalent interaction than by a donor-acceptor interaction. This is in agreement with the NBO results, which indicate that the $\sigma$ bond is more polarized towards the carbenoid end due to its high electronegativity. Consequently, the nucleophilic resonance form depicted in Fig. 5 would provide a more appropriate

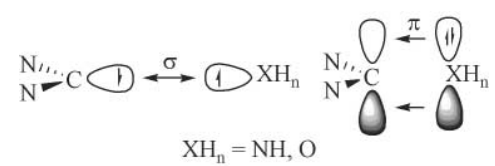

Fig. 5 Schematic representation of the dominant orbital interactions corresponding to a nucleophilic resonance form.

description of the bonding scheme. This bonding model corresponds to the ones suggested by Cundari and Gordon in their study of Schrock carbene complexes. ${ }^{40}$

Finally, the different structural shapes of $\mathbf{1}$ and $\mathbf{2}$ could be interpreted in view of these results. As noted previously, the preparation energy necessary to adapt the $\mathrm{CH}_{2}$ fragment in the adequate configuration for a planar donor-acceptor bond, compared to a perpendicular donor-acceptor bond as in $\mathbf{2}$, is $287 \mathrm{~kJ} \mathrm{~mol}^{-1}$. In the case of the $\mathrm{SiH}_{2}$ fragment, the same calculation gives an excitation energy of $470 \mathrm{~kJ} \mathrm{~mol}^{-1}$. The higher preparative (excitation) energy would likely explain the preferential orientation of the $\mathrm{SiH}_{2}$ moiety.

\section{Conclusion}

We may propose qualitative answers to the questions examined at the beginning of this study. The donor-acceptor description of the bonding for carbene-phosphinidene adducts proposed by Cowley and collaborators may be extended to the $\mathrm{CH}_{2}, \mathrm{SiH}_{2}$ and $\mathrm{S}$ carbenoid moieties. However this donor-acceptorbonding mode not only consists of a $\sigma$ donation from the aminocarbene, but also substantial $\pi$ back-bonding of the carbenoid moiety. The observed carbene-carbenoid bond length is related to the back-donation capability of the 
carbenoid end. The non-planarity observed in the case of the $\mathrm{SiH}_{2}$ fragment, contrary to the $\mathrm{CH}_{2}$ fragment, should be understood in terms of excitation energy. When dealing with $\mathrm{NH}$ and $\mathrm{O}$ fragments, the high electronegativity of the heteroatom yields a $\sigma$-covalent bond and the donor-acceptor model is no longer valid and is better replaced by a nucleophilic limiting form.

\section{References}

1 (a) A. J. Arduengo III, R. L. Harlow and M. Kline, J. Am. Chem Soc., 1991, 113, 361; (b) A. J. Arduengo III, Acc. Chem. Res., 1999, 32, 913.

2 (a) W. A. Herrmann and C. Köcher, Angew. Chem., Int. Ed. Engl., 1997, 36, 2163; (b) T. Weskamp, V. P. W. Böhm and W. A. Herrmann, J. Organomet. Chem., 2000, 600, 12; (c) T. Weskamp, W. C. Schattenmann, M. Spiegler and W. A. Herrmann, Angew. Chem., Int. Ed. Engl., 1998, 37, 2490; (d) J. Huang, E. D. Stevens, S. P. Nolan and J. L. Petersen, J. Am. Chem. Soc., 1999, 121, 2674 (e) M. Scholl, T. M. Trnka, J. P. Morgan and R. H. Grubbs, Tetrahedron Lett., 1999, 40, 2247; $(f)$ W. A. Herrmann, C.-P. Reisinger and M. Spiegler, J. Organomet. Chem., 1998, 557, 93; (g) C. Zhang, J. Huang, M. L. Trudell and S. P. Nolan, J. Org. Chem., 1999, 64, 3804; (h) S. R. Stauffer, S. Lee, J. P. Stambuli, S. I. Hauck and J. F. Hartwig, Org. Lett., 2000, 2, 1423.

3 (a) D. Bourissou, O. Guerret, F. P. Gabbaï and G. Bertrand, Chem. Rev., 2000, 100, 39; (b) C. J. Carmalt and A. H. Cowley, Adv. Inorg. Chem., 2000, 50, 1.

4 N. Kuhn, H. Bohnen, J. Kreutzberg, D. Bläser and R. Boese, J. Chem. Soc., Chem. Commun., 1993, 1136.

5 A. J. Arduengo III, F. Davidson, H. V. R. Dias, J. R. Goerlich, D. Khasnis, W. J. Marshall and T. K. Prakasha, J. Am. Chem. Soc., 1997, 119, 12742.

6 W. M. Boesveld, B. Gehrhus, P. B. Hitchcock, M. F. Lappert and P. v. R. Schleyer, Chem. Commun., 1999, 755.

7 A. J. Arduengo III, H. V. R. Dias, J. C. Calabrese and F. Davidson, Inorg. Chem., 1993, 32, 1541.

8 (a) A. Schäfer, M. Weidenbruch, W. Saak and S. Pohl, J. Chem. Soc. Chem. Commun., 1995, 1157; (b) N. Kuhn, T. Kratz, R. Bläser and R. Boese, Chem. Ber., 1995, 128, 245.

9 F. Stabenow, W. Saak and M. Weidenbruch, Chem. Commun., 1999, 1131.

10 N. Kuhn, R. Fawzi, M. Steimann, J. Wiethoff, D. Bläser and R. Boese, Z. Naturforsch., B: Chem. Sci., 1995, 50, 1779.

11 A. J. Arduengo III, H. V. R. Dias and J. C. Calabrese, Chem. Lett., $1997,143$.

12 A. J. Arduengo III, J. C. Calabrese, A. H. Cowley, H. V. R. Dias, J. R. Goerlich, W. J. Marshall and B. Riegel, Inorg. Chem., 1997, 36, 2151.

13 (a) C. Glidewell, H. D. Holden and D. C. Liles, J. Mol. Struct., 1980, 66, 325; (b) D. Enders, K. Breuer, G. Raabe, J. Runsink, J. H. Teles, J. P. Melder, K. Ebel and S. Brode, Angew. Chem., Int. Ed. Engl., 1995, 34, 1021.

14 (a) G. B. Ansell, D. M. Forkey and D. W. Moore, J. Chem. Soc., Chem. Commun., 1970, 56; (b) G. B. Ansell, J. Chem. Soc., Perkin Trans. 2, 1972, 841; (c) E. S. Raper, A. R. W. Jackson and D. J. Gardiner, Inorg. Chim. Acta, 1984, 84, L1.

15 (a) D. J. Williams, M. R. Fawcett-Brown, R. R. Raye, D. V. Derveer, Y. T. Pang, R. L. Jones and K. L. Bergbauer, Heteroat. Chem., 1993 , 4, 409; (b) N. Kuhn, G. Henkel and T. Kratz, Z. Naturforsch., B: Chem. Sci. 1993, 48, 973

16 N. Kuhn, G. Henkel and T. Kratz, Chem. Ber., 1993, 126, 2047.

17 (a) T. E. Taylor and M. B. Hall, J. Am. Chem. Soc., 1984, 106, 1576; (b) S. F. Vyboishchikov and G. Frenking, Chem. Eur. J., 1998, 4, 1428.

18 (a) A. J. Arduengo III, C. J. Carmalt, J. A. C. Clyburne, A. H. Cowley and R. Pyati, Chem. Commun., 1997, 981; (b) A. Decken, C. J. Carmalt, J. A. C. Clyburne and A. H. Cowley, Inorg. Chem., 1997, 36, 3741.
19 A. J. Arduengo III, J. R. Goerlich and W. J. Marshall, Liebigs Ann., $1997,365$.

20 (a) G. Frison and A. Sevin, J. Phys. Chem. A, 1999, 103, 10998; (b) G. Frison and A. Sevin, J. Organomet. Chem., 2002, 643-644, 105.

21 M. J. Frisch, G. W. Trucks, H. B. Schlegel, P. M. W. Gill, B. G. Johnson, M. A. Robb, J. R. Cheeseman, T. Keith, G. A. Petersson, J. A. Montgomery, K. Raghavachari, M. A. Al-Laham, V. G. Zakrzewski, J. V. Ortiz, J. B. Foresman, J. Cioslowski, B. B. Stefanov, A. Nanayakkara, M. Challacombe, C. Y. Peng, P. Y. Ayala, W. Chen, M. W. Wong, J. L. Andres, E. S. Replogle, R. Gomperts, R. L. Martin, D. J. Fox, J. S. Binkley, D. J. Defrees, J. Baker, J. P. Stewart, M. Head-Gordon, C. Gonzalez and J. A. Pople, GAUSSIAN 94, Revision D.4, Gaussian, Inc., Pittsburgh, PA, 1995

22 M. J. Frisch, G. W. Trucks, H. B. Schlegel, G. E. Scuseria, M. A. Robb, J. R. Cheeseman, V. G. Zakrzewski, J. A. Montgomery Jr., R. E. Stratmann, J. C. Burant, S. Dapprich, J. M. Millam, A. D. Daniels, K. N. Kudin, M. C. Strain, O. Farkas, J. Tomasi, V. Barone, M. Cossi, R. Cammi, B. Mennucci, C. Pomelli, C. Adamo, S. Clifford, J. Ochterski, G. A. Petersson, P. Y. Ayala, Q. Cui, K. Morokuma, D. K. Malick, A. D. Rabuck, K. Raghavachari, J. B. Foresman, J. Cioslowski, J. V. Ortiz, A. G. Baboul, B. B. Stefanov, G. Liu, A. Liashenko, P. Piskorz, I. Komaromi, R. Gomperts, R. L. Martin, D. J. Fox, T. Keith, M. A. Al-Laham, C. Y. Peng, A. Nanayakkara, C. Gonzalez, M. Challacombe, P. M. W. Gill, B. Johnson, W. Chen, M. W. Wong, J. L. Andres, C. Gonzalez, M. Head-Gordon, E. S. Replogle and J. A. Pople, GAUSSIAN 98, Revision A.7, Gaussian, Inc., Pittsburgh, PA, 1998.

23 (a) A. D. Becke, J. Chem. Phys., 1993, 98, 5648; (b) C. Lee, W. Yang and R. G. Parr, Phys. Rev. B, 1988, 37, 785.

24 P. C. Hariharan and J. A. Pople, Theor. Chim. Acta, 1973, 28, 213.

25 (a) J. P. Foster and F. Weinhold, J. Am. Chem. Soc., 1980, 102, 7211; (b) A. E. Reed and F. Weinhold, J. Chem. Phys., 1985, 83, 1736.

26 (a) A. E. Reed, L. A. Curtiss and F. Weinhold, Chem. Rev., 1988, 88, 899; (b) S. Dapprich and G. Frenking, J. Phys. Chem., 1995, 99, 9352.

27 (a) A. D. Becke and K. E. Edgecombe, J. Chem. Phys., 1990, 92, 5397; (b) B. Silvi and A. Savin, Nature, 1994, 371, 683.

28 S. Noury, X. Krokidis, F. Fuster and B. Silvi, TopMod package, Université Pierre et Marie Curie, 1997. Available free of charge at http://www.lct.jussieu.fr/silvi.

29 (a) M. J. S. Dewar, Bull. Soc. Chim. Fr., 1951, 18, C71; (b) J. Chatt and L. A. Duncanson, J. Chem. Soc., 1953, 2939.

30 S. Dapprich and G. Frenking, CDA 2.1, Marburg, 1994.

31 (a) P. v. R. Schleyer, C. Maerker, A. Dransfeld, H. Jiao and N. J. R. v. E. Hommes, J. Am. Chem. Soc., 1996, 118, 6317; (b) P. v. R. Schleyer, H. Jiao, N. J. R. v. E. Hommes, V. G. Malkin and O. L. Malkina, J. Am. Chem. Soc., 1997, 119, 12669.

32 (a) C. W. Bauschlicher, Jr. and H. Partridge, J. Chem. Phys., 1995, 103, 1788; (b) M. W. Wong, Chem. Phys. Lett., 1996, 256, 391.

33 Unsubstituted imidazolin-2-ylidene calculated at the same level shows bond lengths as follows: $\mathrm{C}(1)-\mathrm{N}(2)=\mathrm{C}(1)-\mathrm{N}(5)=1.372 \AA$, $\mathrm{C}(2)-\mathrm{N}(3)=\mathrm{C}(4)-\mathrm{N}(5)=1.394 \AA, \mathrm{C}(3)-\mathrm{C}(4)=1.356 \AA$. NICS calculated at the center of the ring has the value -12.7 . Population ELF: 2.46 e in $\mathrm{V}(\mathrm{C} 1), 2.49$ e in $\mathrm{V}(\mathrm{C} 1, \mathrm{~N} 2 / 5), 1.93 \mathrm{e}$ in $\mathrm{V}(\mathrm{N} 2 / 5, \mathrm{C} 3 / 4)$, 3.58 e in $\mathrm{V}(\mathrm{C} 3, \mathrm{C} 4), 0.98$ in $\mathrm{V}(\mathrm{N} 2 / 5)$.

34 (a) C. Heinemann, T. Müller, Y. Apeloig and H. Schwarz, J. Am. Chem. Soc., 1996, 118, 2023; (b) C. Boehme and G. Frenking, J. Am. Chem. Soc., 1996, 118, 2039.

35 To constrain the NBO procedure to calculate the other structures A-C (Fig. 1) always gives lower valence Lewis orbital occupation.

36 D. B. Chesnut and L. J. Bartolotti, Chem. Phys., 2000, 253, 1

37 G. Frison, F. Mathey and A. Sevin, J. Phys. Chem. A, 2002, 106, 5653.

38 I. Fourré, B. Silvi, P. Chaquin and A. Sevin, J. Comput. Chem., 1999, 20, 897.

39 H. Grützmacher and T. F. Fässler, Chem. Eur. J., 2000, 6, 2317

40 (a) T. R. Cundari and M. S. Gordon, J. Am. Chem. Soc., 1991, 113, 5231; (b) T. R. Cundari and M. S. Gordon, J. Am. Chem. Soc., 1992, 114, 539 . 